\title{
Erratum to: Quantitation and Risk Assessment of Chemical Adulterants in Milk Using UHPLC Coupled to Photodiode Array and Differential Refractive Index Detectors
}

\author{
Sheikh Asrar Ahmad ${ }^{1}$. Mahmood Ahmed ${ }^{2}$ Muhammad Abdul Qadir ${ }^{2}$. \\ Muhammad Imtiaz Shafiq $^{4} \cdot$ Nafeesa Batool $^{1} \cdot$ Nazra Nosheen $^{1} \cdot$ Muhammad Ahmad $^{1}$ • \\ Rana Khalid Mahmood ${ }^{3} \cdot$ Zia Ullah Khokhar $^{3}$
}

Published online: 18 May 2016

(C) Springer Science+Business Media New York 2016

Erratum to: Food Anal. Methods (2016)

DOI 10.1007/s12161-016-0534-2

The original version of this article unfortunately contained the following errors.

The spelling of Muhammad Imtiaz Shafiq name was incorrect.

In keywords, "Area" was captured instead of "Urea".

The online version of the original article can be found at http://dx.doi.org/ 10.1007/s12161-016-0534-2.

\footnotetext{
Mahmood Ahmed

mahmoodresearchscholar@gmail.com

1 Division of Science and Technology, University of Education, Lahore, Pakistan

2 Institute of Chemistry, University of the Punjab, Lahore 54590 , Pakistan

3 Government Post graduate Islamia College Gujranwala, Gujranwala, Pakistan

4 Institute of Biochemistry and Biotechnology, University of the Punjab, Lahore 54590, Pakistan
} 